\title{
Satellite lesions accompanying herpes zoster: a new prognostic sign for high-risk zoster*
}

\author{
L. el Hayderi, ${ }^{1}$ S. Bontems, ${ }^{2}$ N. Nikkels-Tassoudji, ${ }^{1}$ J.E. Arrese, ${ }^{3}$ L. Seidel,,${ }^{4}$ C. Meex $^{2}$ and A.F. Nikkels ${ }^{1}$ \\ Departments of ${ }^{1}$ Dermatology, ${ }^{2}$ Fundamental Virology, ${ }^{3}$ Dermatopathology and ${ }^{4}$ Biostatistics, University of Liège, B-4000 Liège, Belgium
}

\section{Summary}

\section{Correspondence \\ Arjen F. Nikkels. \\ E-mail: af.nikkels@chu.ulg.ac.be}

\section{Accepted for publication \\ 20 December 2014}

\section{Funding sources}

None.

\section{Conflicts of interest}

None declared.

*Plain language summary available online.

DOI 10.1111/bjd.13643
Background The incidence, clinical relevance and pathogenesis of single, isolated, varicella-like skin lesions occurring far beyond the primary herpes zoster (HZ)affected dermatome remain unclear.

Objectives To search prospectively for these satellite lesions in 120 patients with $\mathrm{HZ}$ and to correlate their presence with a series of clinical, histological and virological data.

Methods Relevant clinical data were recorded from 109 patients with proven HZ using immunohistochemistry on Tzanck smears. Furthermore, skin biopsies and blood samples were obtained from a subgroup of patients presenting with primary HZ with and without satellite lesions for histology, immunohistology, serology and real-time polymerase chain reaction.

Results This study identified satellite lesions in $21 \cdot 1 \%$ of the patients with HZ. Their presence conveyed a statistically significant relative risk (RR) for severe (RR 3.27, $\mathrm{P}<0.001$ ), multidermatomal (RR 10.6, $\mathrm{P}<0.001$ ) and multistage HZ (RR $3.30, P<0.001)$; systemic signs (RR 2.08, $P=0.0031)$; immunosuppression (RR $2 \cdot 38, \mathrm{P}=0.0014)$ and hospitalization (RR 2.94, $\mathrm{P}<0.001)$. Varicella zoster virus (VZV) viraemia was higher (mean 4075 copies $\mathrm{mL}^{-1}$ ) in patients with $\mathrm{HZ}$ with satellite lesions than in those without (mean 1466 copies $\mathrm{mL}^{-1}$ ). In contrast to $\mathrm{HZ}$ lesions, satellite lesions often presented positive VZV immunostaining in endothelial cells, suggesting a similar pathogenesis to varicella. A limitation of this study is the centre-linked overrepresentation of immunocompromised patients.

Conclusions Total-body examination searching for satellite lesions is a rapid, simple and reliable tool for identifying patients with high-risk HZ.

\section{What's already known about this topic?}

- The clinical relevance of varicella zoster virus satellite lesions occurring during herpes zoster is unclear.

\section{What does this study add?}

- The presence of satellite lesions during herpes zoster conveys a statistically significant increased risk for hospitalization of the patient, an immunosuppressive status, the development of systemic signs, and multistage and multidermatomal herpes zoster.

- Total-body examination for satellite lesions is a rapid, easy and reliable clinical tool for identifying patients with high-risk zoster.
The varicella zoster virus (VZV) is responsible for chickenpox and shingles. ${ }^{1}$ Occasionally, patients with herpes zoster (HZ) present simultaneously one or more single, isolated, nonclustered, varicella-like lesions some distance from the primary HZ-afflicted dermatome. ${ }^{2,3}$ The incidence, clinical relevance and pathomechanisms of these VZV satellite lesions (SLs) remain unclear.

This study prospectively examined a series of patients with $\mathrm{HZ}$ for the occurrence of SLs and correlated their presence 
with various clinical, histological, immunohistological, serological and virological features.

\section{Materials and methods}

The university hospital ethics committee authorized the study, and all patients signed an informed consent.

The incidence of SLs among patients with HZ was prospectively studied over a 2·5-year period (October 2011 to February 2014) in a university medical referral centre. Patients already taking antiviral therapy were excluded. The clinical diagnosis of HZ was confirmed by immunohistochemistry using VZV-specific anti-gE and anti-gB viral envelope antibodies on a Tzanck smear and/or skin biopsy, following an earlier published protocol. ${ }^{4}$ Antiherpes simplex virus type I and II antibodies were used to rule out zosteriform herpes simplex infections. ${ }^{4}$ The included patients with HZ were specifically screened for SLs, defined as small, isolated, nonclustered, varicella-like skin lesions occurring at least $5 \mathrm{~cm}$ away from the primary $\mathrm{HZ}$ dermatome.

Collected clinical data included age, sex, the dermatome group affected by the primary HZ (cephalic, cervical, thoracic, lumbar or sacral), the grade of surface of the dermatome(s) involved by the primary $\mathrm{HZ}$ skin lesions [grade 1, isolated cluster(s) $<10 \mathrm{~cm}^{2}$; grade 2, lesion cluster(s) $10-50 \mathrm{~cm}^{2}$; grade 3 , lesion cluster(s) $\left.>50 \mathrm{~cm}^{2}\right]$, single or multiple adjacent dermatomes of the primary HZ, single-stage (papular, vesicular, pustular or crusted skin lesions) or multistage primary HZ (simultaneous presence of both papular, vesicular, pustular and/or crusted cutaneous lesions), prodromal and/or concomitant pain, systemic signs (fever, malaise, lymphadenopathies and/or headache), underlying immunosuppression and hospitalization for antiviral treatment.

The relative risks (RRs) that SLs provided for any of the above-mentioned clinical features in a patient with HZ were calculated, with 95\% confidence intervals (CIs) and P-values. Results were considered to be significant at $\mathrm{P}<0.05$. When considering the $\mathrm{RR}$ of $3 \cdot 15$ and a reference proportion of $0 \cdot 12$ (nine of 73 with SLs among nonimmunosuppressed subjects), and sample groups of 36 (immunocompromised) and 73 (nonimmunocompromised) patients, with $\alpha=0.05$, the power is equal to $0 \cdot 835$.

To gain insight into the pathogenesis of SLs, the following materials were sampled from a series of patients with HZ with an SL at the time of diagnosis: skin biopsies from primary HZ $(\mathrm{n}=15)$, skin biopsies from an SL $(\mathrm{n}=14)$ and $10-\mathrm{mL}$ ethylenediaminetetraacetic acid (EDTA)-blood samples $(\mathrm{n}=14)$ for serology and reverse-transcriptase polymerase chain reaction (rt-PCR). For comparison, skin biopsies from primary $\mathrm{HZ}$ $(\mathrm{n}=17)$ and 10-mL EDTA-blood samples $(\mathrm{n}=20)$ were collected from patients with HZ without SLs at the time of diagnosis. Cutaneous biopsies were available from four of the eight patients with varicella.

Histology was used to assess epidermal and/or infundibular cytopathic effects with giant-cell formation and/or intranuclear inclusions, eventual perivascular lymphohistiocytic infiltrates and signs of vasculitis.
Immunohistology was performed on skin biopsies using anti-gE and anti-gB antibodies following an earlier published protocol. ${ }^{4}$ VZV serology was evaluated using a VZV-specific IgG and IgM enzyme-linked immunosorbent assay (ELISA). VZV viraemia was assessed and quantified by VZV-open reading frame 21-based rt-PCR according to a previously reported protocol. ${ }^{5}$ For the immunohistochemical, ELISA and rt-PCR assays, patients with varicella $(n=8)$, patients with orolabial herpes $(n=4)$ and healthy subjects $(n=6)$ were included as controls.

\section{Results}

In total, 120 patients had a clinical suspicion of HZ, which was confirmed by immunohistochemical screening in 109 . Thirty-six patients were immunocompromised. Among those with HZ with SLs this was due to: haemopathies $(n=6)$ (three chronic lymphocytic leukaemia, one acute lymphocytic leukaemia, one acute myeloid leukaemia and one myelodysplastic syndrome); solid organ transplant $(\mathrm{n}=2$ renal and 1 cardiac); bone marrow transplant $(n=2) ; \operatorname{HIV}(n=1)$; and chemotherapy for breast cancer $(n=2)$. Among those with HZ without SLs this was due to: haemopathies ( $\mathrm{n}=3$ ) (two chronic lymphocytic leukaemia and one acute myeloid leukaemia); solid organ transplant $(n=3$ renal); bone marrow transplant $(\mathrm{n}=5)$; HIV $(\mathrm{n}=1)$; metastatic prostate cancer $(n=2)$; chemotherapy for small cell lung cancer $(n=1)$, breast cancer $(n=3)$ or metastatic melanoma $(n=1)$; tumour necrosis factor (TNF) antagonists for rheumatoid arthritis $(\mathrm{n}=2)$ and TNF antagonists combined with oral corticosteroids for hidradenitis suppurativa $(n=1)$.

SLs were observed in 23 of $109(21 \cdot 1 \%)$ of the patients. Among the patients with HZ with SLs, nine were immunocompetent (mean age 69.3 years, range 28-88, median 77 ) and 14 were immunocompromised (mean age 59.9 years, range $22-$ 82 , median $61 \cdot 5)$. Of all the included immunocompromised patients with HZ, 39\% presented SLs (mean age 61.1 years, range $22-91$, median $61 \cdot 5$ ), vs. $12 \%$ of the 73 immunocompetent patients (mean age 63.9 years, range $24-84$, median 68 ). Hence, immunocompromised patients with $\mathrm{HZ}$ presented a 3.15-fold increased RR of exhibiting SLs compared with immunocompetent patients (95\% CI 1.51-6.59, P = 0.0014).

The number of SLs ranged from five to 40 . Immunocompromised patients with HZ presented significantly more SLs (mean 27.3, range 10-40) than immunocompetent patients with $\mathrm{HZ}$ (mean $11 \cdot 7$, range 5-21). The lesions presented as clear or pustular vesicles with a central depression, sometimes crusted and/or ulcerated, and were occasionally slightly haemorrhagic (Fig. 1). The most frequent localization of SLs was the trunk (20 of 23), with others on the head and neck area (one of 23) and the extremities (two of 23). The SLs were not pruritic or painful. The other clinical results for patients with and without SLs are presented in Table 1. The patients received an antiviral treatment: oral aciclovir, oral valaciclovir or intravenous aciclovir. No case of motor paresis or systemic or lethal disseminated VZV disease was recorded. 


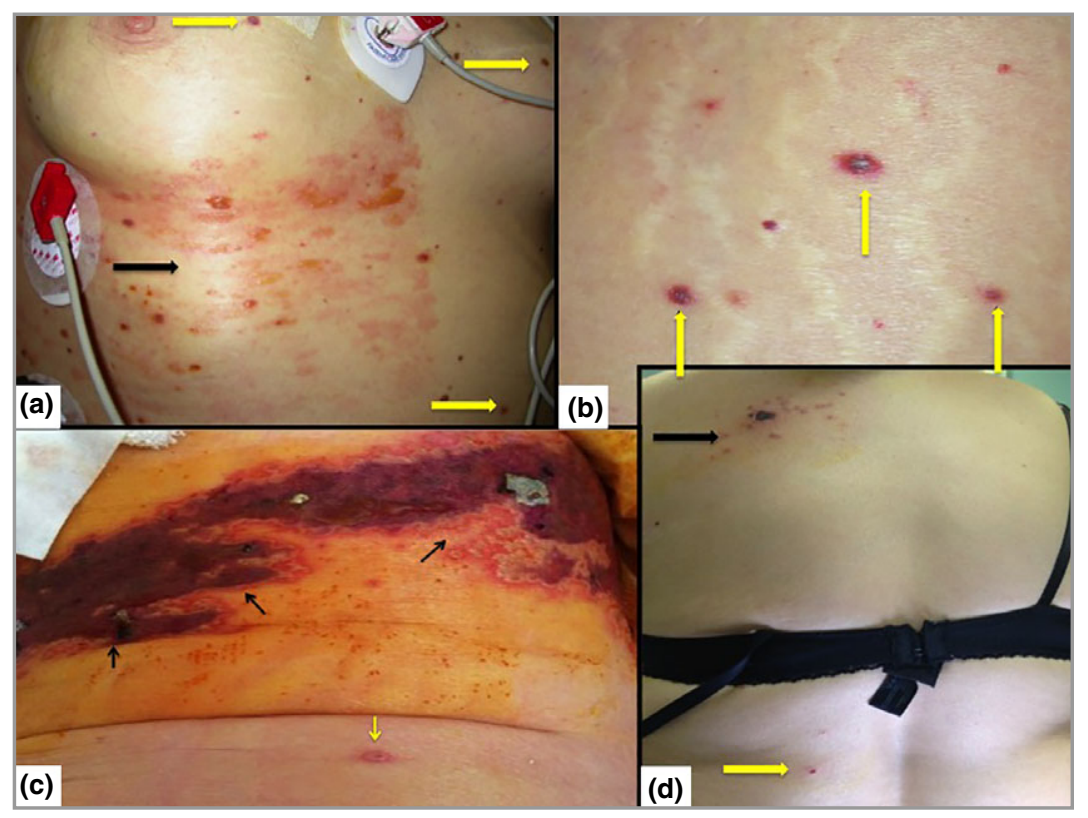

Fig 1. (a) Primary herpes zoster (HZ) of the T5,6 dermatomes and (b) high-power magnification of the satellite lesions. (c) Primary HZ of the T7,8 dermatomes. (d) Primary HZ of the T1 dermatome. Black arrows, primary HZ; yellow arrows, satellite lesions.
Table 1 Clinical features of patients with herpes zoster (HZ) with and without satellite lesions

\begin{tabular}{|c|c|c|}
\hline & $\begin{array}{l}\text { HZ without satellite } \\
\text { lesions, } n=86\end{array}$ & $\begin{array}{l}\text { HZ with satellite } \\
\text { lesions, } n=23\end{array}$ \\
\hline Mean age (years) & $57 \cdot 9$ & $60 \cdot 9$ \\
\hline Sex (male/female) & $41 / 45$ & $11 / 12$ \\
\hline \multicolumn{3}{|l|}{ Dermatome } \\
\hline Cephalic & $22(26)$ & $9(39)$ \\
\hline Cervical & $10(12)$ & $3(13)$ \\
\hline Thoracic & $45(52)$ & $7(30)$ \\
\hline Lumbar & $7(8)$ & $4(17)$ \\
\hline Sacral & $2(2)$ & 0 \\
\hline \multicolumn{3}{|l|}{ HZ surface involvement ${ }^{\mathrm{a}}$} \\
\hline Grade 1 & $25(29)$ & $2(9)$ \\
\hline Grade 2 & $35(41)$ & $7(30)$ \\
\hline Grade 3 & $16(19)$ & $14(60)$ \\
\hline \multicolumn{3}{|l|}{ Dermatomes } \\
\hline Single & $80(93)$ & $7(30)$ \\
\hline Multiple & $6(7)$ & $16(70)$ \\
\hline \multicolumn{3}{|l|}{ NZ stages } \\
\hline Single stage & $69(80)$ & $7(30)$ \\
\hline Multistage & $17(20)$ & $16(70)$ \\
\hline $\begin{array}{l}\text { Prodromal and } \\
\text { concomitant pains }\end{array}$ & $53(62)$ & $15(65)$ \\
\hline Systemic signs ${ }^{b}$ & $27(31)$ & $13(57)$ \\
\hline Immunosuppression & $22(26)$ & $14(60)$ \\
\hline $\begin{array}{l}\text { Hospitalization for oral } \\
\text { or intravenous } \\
\text { antiviral therapy }\end{array}$ & $14(16)$ & $10(43)$ \\
\hline $\begin{array}{l}\text { Values are } \mathrm{n}(\%) .{ }^{\mathrm{a}} \mathrm{HZ} \text { surfa } \\
\text { clusters }<10 \mathrm{~cm}^{2} \text {; grade } 2 \\
>50 \mathrm{~cm}^{2} .{ }^{\mathrm{b}} \text { Fever, lympha }\end{array}$ & $\begin{array}{l}\text { ce involvement grades: } \\
\text { clusters } 10-50 \mathrm{~cm}^{2} \\
\text { lenopathies, malaise ar }\end{array}$ & $\begin{array}{l}\text { grade } 1 \text {, lesion } \\
\text { rrade } 3 \text {, clusters } \\
\text { d/or headache. }\end{array}$ \\
\hline
\end{tabular}

The statistically significant RRs for the presence of SLs conveyed in a given patient with $\mathrm{HZ}$ are as follows. Systemic signs, RR 2.08 (95\% CI 1.35-3.30, P = 0.0031); immunosuppres- sion, RR $2 \cdot 38$ (95\% CI 1.46-3.87, P = 0.0014); multistage HZ, RR 3.30 (95\% CI 1.96-5.55, P < 0.001); multidermatomal HZ, RR 10.6 (95\% CI 4.72-23.8, P < 0.001); HZ surface involvement grade 3, RR 3.27 (95\% CI 1.89-5.67, P < 0.001) and hospitalization, RR 2.94 (95\% CI 1.55-5.58, P < 0.001).

The histological alterations of the epidermis were similar between HZ, SLs, varicella and herpes simplex (Fig. 2a,b and Table 2). Immunohistology demonstrated an epidermal VZV $\mathrm{gE}$ and $\mathrm{gB}$ distribution pattern that was indistinguishable between HZ lesions, SLs and varicella skin lesions (Fig. 2c,d) (Table 2).

A variably dense lymphohistiocytic perivascular dermal infiltrate was present in nearly all of the cases of $\mathrm{HZ}$ with and without SLs. In contrast, SLs showed a higher number of vasculitic changes than the HZ lesions (Table 2). The skin lesions from the primary HZ site from patients with and without SLs showed positive VZV immunostaining in the dermal dendrocytes of the upper reticular dermis, but not in the perivascular dermal dendrocytes and endothelial cells (Fig. 2c) (Table 2). Positive VZV immunostaining of endothelial cells and perivascular dermal dendrocytes was seen in all cases of varicella, in more than half of the cases with SLs (Fig. 2d) and in only one case of HZ (Table 2).

All patients with HZ with and without SLs showed positive VZV-specific IgG and negative IgM levels, indicating a status of past varicella infection and ruling out cases of primary contact with VZV.

The mean viral copy number was lower in the patients with HZ without SLs compared with those with SLs: 1466 copies $\mathrm{mL}^{-1}$ (range 49-7192) vs. 4075 copies $\mathrm{mL}^{-1}$ (range 4023 139), respectively. Immunocompromised patients with HZ with SLs also presented a higher mean number of viral copies than immunocompetent patients (6970 vs. 730 copies $\mathrm{mL}^{-1}$, respectively). Patients with varicella presented a high-load VZV viraemia (mean 30431 copies $\mathrm{mL}^{-1}$ (range 1835-107 673). 
Fig 2. (a) Epidermal cytopathic effects during herpes zoster (HZ). (b) Epidermal cytopathic effects in a satellite lesion. (c) Epidermal (black arrow) and dermal dendrocyte (red arrow) varicella zoster virus (VZV)

immunostaining in the reticular dermis of an HZ skin lesion. Absence of VZV

immunostaining in the small vessels (blue arrow). (d) Epidermal VZV immunostaining of the epidermis (black arrow), dermal dendrocytes (red arrow) and in the superficial vascular plexus (yellow arrows).

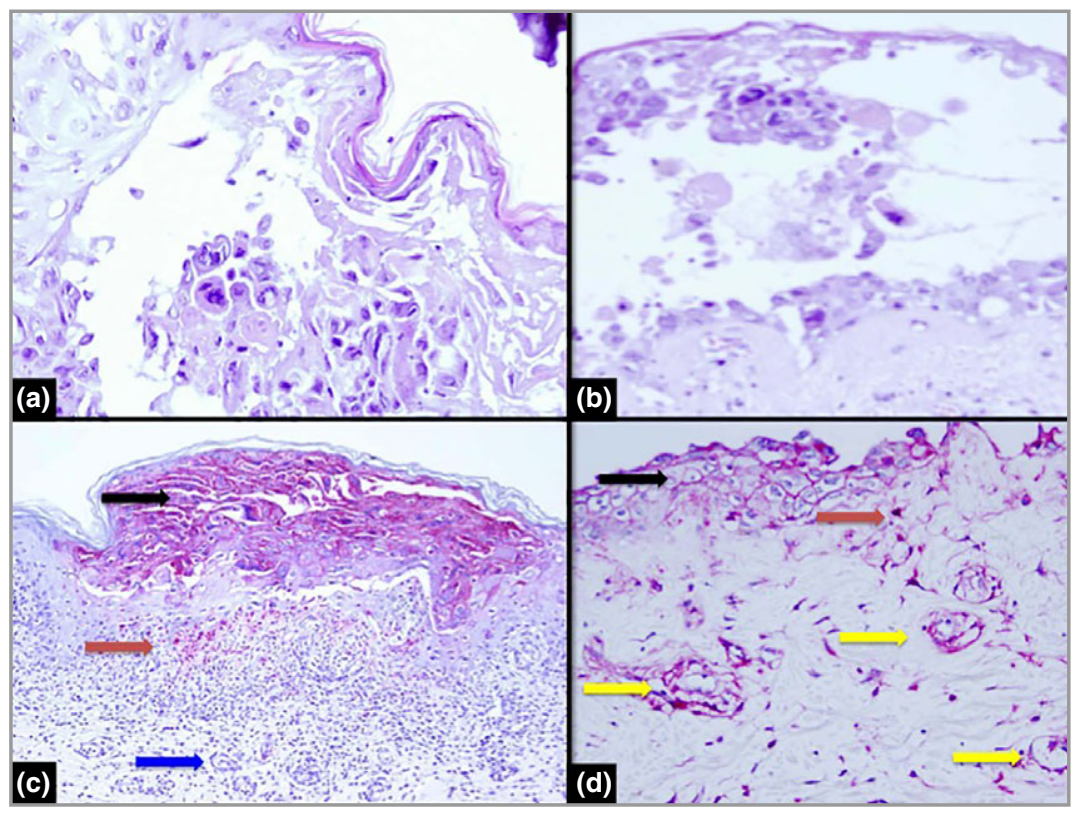

Table 2 Results of histology and immunohistochemistry

\begin{tabular}{|c|c|c|c|c|}
\hline & & HZ without satellite lesions & HZ with satellite lesions & Varicella \\
\hline \multicolumn{5}{|l|}{ Histology } \\
\hline \multirow[t]{3}{*}{ HZ skin lesions } & Epidermal cytopathic effects & $17 / 17(100)$ & $15 / 15(100)$ & $4 / 4(100)$ \\
\hline & $\begin{array}{l}\text { Perivascular } \\
\text { lymphohistiocytic infiltrate }\end{array}$ & $15 / 17(88)$ & $14 / 15(93)$ & $4 / 4(100)$ \\
\hline & Signs of vasculitis & $1 / 17(6)$ & $0 / 15(0)$ & $3 / 4(75)$ \\
\hline \multirow[t]{3}{*}{ Satellite lesions } & Epidermal cytopathic effects & NA & $14 / 14(100)$ & NA \\
\hline & $\begin{array}{l}\text { Perivascular } \\
\text { lymphohistiocytic infiltrate }\end{array}$ & & $14 / 14(100)$ & \\
\hline & Signs of vasculitis & & $6 / 14(42)$ & \\
\hline \multicolumn{5}{|c|}{ Immunohistochemistry (positive $\mathrm{gE}$ and $\mathrm{gB}$ signal) } \\
\hline \multirow[t]{3}{*}{ HZ skin lesions } & $\begin{array}{l}\text { Epidermal and/or } \\
\text { infundibular keratinocytes }\end{array}$ & $17 / 17(100)$ & $15 / 15(100)$ & $4 / 4(100)$ \\
\hline & Perivascular dermal dendritic cells & $1 / 17(58)$ & $1 / 15(66)$ & $4 / 4(100)$ \\
\hline & Endothelial cells & $1 / 17(58)$ & $1 / 15(66)$ & $4 / 4(100)$ \\
\hline \multirow[t]{3}{*}{ Satellite lesions } & Epidermal and/or infundibular keratinocytes & $\mathrm{NA}$ & $14 / 14(100)$ & NA \\
\hline & Perivascular dermal dendritic cells & & $8 / 14(57)$ & \\
\hline & Endothelial cells & & $8 / 14(57)$ & \\
\hline
\end{tabular}

All positive and negative controls were consistently positive and negative.

\section{Discussion}

This study revealed that SLs occurred 3.15 times more frequently in immunocompromised patients with $\mathrm{HZ}$ than in immunocompetent patients. About $21 \%$ of all included patients with HZ presented one or more SL. This percentage may be overestimated due to the tertiary-care setting, which probably receives the more severe cases of HZ. This study also demonstrated that SLs in a given patient with HZ increase the RR for developing systemic signs, multidermatomal HZ, mul- tistage $\mathrm{HZ}$ and extensive cutaneous involvement, and for hospitalization and immunosuppression, all representing typical clinical predictors for severe $\mathrm{HZ}$ that could potentially progress to organ- and life-threatening dissemination. In summary, SLs in a patient with $\mathrm{HZ}$ emerge as a novel clinical predictor of high-risk HZ disease.

SLs might be mistaken for disseminated cutaneous lesions of primary HZ. However, several arguments support that SLs originate through vascular dissemination of VZV particles and are hence not related to the neural pathway of HZ. Firstly, there is the striking clinical similarity between SLs and varicella lesions. Secondly, no clustered SLs or SLs in a dermatomal pattern were observed, contrasting with HZ. Finally, 
histology revealed vasculitic alterations in three of four varicella lesions and in $42 \%$ of the 14 SLs, but in only one of 32 cases of HZ. In addition, immunohistochemistry demonstrated VZV gE and gB in endothelial cells and perivascular dermal dendritic cells in $57 \%$ of the SLs. These data suggest VZV viraemia in patients with HZ with SL. Indeed, in $57 \%$ of the patients with SLs, a VZV viraemia was measured, with a mean viral load of 4075 copies $\mathrm{mL}^{-1}$. The patients with $\mathrm{HZ}$ not exhibiting SLs presented a viraemia in only $50 \%$ of cases, and the viral load was significantly lower (1466 copies $\mathrm{mL}^{-1}$ ). In contrast, all patients with varicella presented a significant viral load (30 431 copies $\mathrm{mL}^{-1}$ ).

Previous studies demonstrated transitory VZV viraemia with a low viral load in some immunocompetent patients with acute $\mathrm{HZ}$, and the presence of VZV DNA in all of the immunocompromised patients. ${ }^{6,7}$ The viral load clearly correlated with the severity of VZV disease. ${ }^{8-14}$ Even if the literature is not always consistent, due to a wide variability of PCR techniques and sampling time points, most studies ${ }^{7-11}$ suggest that a higher VZV viral load is associated with more severe immunosuppression and/or HZ severity. This is in accordance with our results.

In conclusion, total-body examination searching for SLs in a patient with HZ is a novel, rapid, simple, efficient and reliable clinical tool for identifying patients with high-risk HZ. SLs probably share the same pathogenic mechanisms as varicella skin lesions.

\section{References}

1 Gershon AA, Gershon MD. Pathogenesis and current approaches to control of varicella-zoster virus infections. Clin Microbiol Rev 2013; 26:728-43.

2 Gupta S, Gupta S, Thomas M et al. Herpes Zoster with disseminated lesions. What is it? J Med Life 2013; 6:84-5.
3 Mabuchi T, Yamaoka H, Kato M et al. Case of disseminated vesicles of herpes zoster developing one day before the onset of local eruption in a hospitalized immunocompromised patient. Tokai J Exp Clin Med 2013; 38:52-4.

4 Nikkels AF, Delbecque K, Pierard GE et al. Distribution of varicellazoster virus DNA and gene products in tissues of a first-trimester varicella-infected fetus. J Infect Dis 2005; 191:540-5.

5 Cohrs RJ, Randall J, Smith J et al. Analysis of individual human trigeminal ganglia for latent herpes simplex virus type 1 and varicella-zoster virus nucleic acids using real-time PCR. J Virol 2000; 74:11464-71.

6 Mainka C, Fuss B, Geiger $\mathrm{H}$ et al. Characterization of viremia at different stages of varicella-zoster virus infection. J Med Virol 1998; 56:91-8.

7 de Jong MD, Weel JF, Schuurman T et al. Quantitation of varicellazoster virus DNA in whole blood, plasma, and serum by PCR and electrochemiluminescence. J Clin Microbiol 2000; 38:2568-73.

8 Bezold G, Lange M, Pillekamp H, Peter RU. Varicella zoster viraemia during herpes zoster is not associated with neoplasia. J Eur Acad Dermatol Venereol 2002; 16:357-60.

9 Ishizaki Y, Tezuka J, Ohga S et al. Quantification of circulating varicella zoster virus-DNA for the early diagnosis of visceral varicella. J Infect 2003; 47:133-8.

10 Kronenberg A, Bossart W, Wuthrich RP et al. Retrospective analysis of varicella zoster virus (VZV) copy DNA numbers in plasma of immunocompetent patients with herpes zoster, of immunocompromised patients with disseminated VZV disease, and of asymptomatic solid organ transplant recipients. Transpl Infect Dis 2005; 7:116-21.

11 Kalpoe JS, Kroes AC, Verkerk S et al. Clinical relevance of quantitative varicella-zoster virus (VZV) DNA detection in plasma after stem cell transplantation. Bone Marrow Transplant 2006; 38:41-6.

12 Satyaprakash AK, Tremaine AM, Stelter AA et al. Viremia in acute herpes zoster. J Infect Dis 2009; 200:26-32.

13 Quinlivan ML, Ayres KL, Kelly PJ et al. Persistence of varicella-zoster virus viraemia in patients with herpes zoster. J Clin Virol 2011; 50:130-5.

14 Quinlivan ML, Ayres K, Ran H et al. Effect of viral load on the outcome of herpes zoster. J Clin Microbiol 2007; 45:3909-14. 